\title{
Effect of pulmonary wedge resection on Ia stage non-small cell lung cancer of elderly patients, its effect on serum anti-survivin antibody, Hsp90A and CEA levels.
}

\author{
Run-hua Tian', Chun-xi Zheng ${ }^{2 *}$, Rong-rong Dou ${ }^{3}$, Yun-yuan Zhang1, Xian Chen ${ }^{1}$ \\ ${ }^{1}$ Department of Clinical Laboratory, the Affiliated Hospital of Qingdao University, Qingdao, Shandong, PR China \\ ${ }^{2}$ Qingdao Commercial Worker's Hospital Qingdao, Shangdong, PR China \\ ${ }^{3}$ Hepatobiliary and Pancreatic Surgery Department, the Affiliated Hospital of Qingdao University, PR China
}

\begin{abstract}
Objective: To observe the short-term clinical effect of pulmonary wedge resection in the treatment of primary Non-Small Cell Lung Cancer (NSCLC) and its effect on levels of anti-survivin antibody, Hsp90 $\alpha$ and CEA in serum of patients.

Methods: 32 cases of elderly patients with stage Ia non-small cell lung cancer were treated with thoracoscopic pulmonary wedge resection from January 2013 to January 2016, and 32 cases of healthy subjects were enrolled as control group. The patient's surgical indicators and the relapse after surgery were followed. The levels of anti-Survivin antibody, Hsp90 $\alpha$ and CEA in the serum of the two groups before surgery were compared; the levels of anti-Survivin antibody, Hsp90 $\alpha$ and CEA before and after the operation in the serum of the patients were compared.

Results: The operation time was $38 \sim 98 \mathrm{~min}$, with an average of $71.7 \pm 13.2 \mathrm{~min}$. Intraoperative blood loss was an average of $113.2 \mathrm{ml}$. No open chest surgery cases. Postoperative pulmonary infection occurred in 4 cases. The levels of anti-survivin antibody, Hsp90 $\alpha$ and CEA in the serum of the observation group before surgery were significantly higher than those in the control group $(P<0.05)$. The anti-survivin antibody, Hsp90 $\alpha$ and CEA levels in serum of patients after surgery were significantly lower than those before operation $(\mathbf{P}<\mathbf{0 . 0 5})$. The three indexes of patients with recurrent metastases were significantly higher than those without recurrence and metastasis $(P<0.05)$.

Conclusion: Pulmonary wedge resection is effective in the treatment of elderly patients with stage Ia Non-Small Cell Lung Cancer (NSCLC). The levels of anti-Survivin antibody, Hsp90 $\alpha$ and CEA in serum after operation are significantly decreased.
\end{abstract}

Keywords: Non-small cell lung cancer, Pulmonary wedge resection, Tumor markers, Relapse.

Accepted on November 29, 2017

\section{Introduction}

Lung cancer is one of the most common malignant tumors, the incidence was in the first in men, and accounted for the second in women. At the same time lung cancer is also one of malignant tumors with the fastest growing mortality [1]. Nonsmall cell lung cancer accounts for nearly $80 \%$ of lung cancer, pathological types, including squamous cell carcinoma, adenocarcinoma, etc., and has slower development and spread relative to small cell carcinoma [2]. Surgical treatment is the preferred and main treatment for non-small cell lung cancer [3]. For lung cancer surgery, lobectomy is the standard method. However, lobectomy has large trauma, and does harm to lung function, so wedge resection as a less invasive way attracts more and more attention [4]. Resection of the tumor and adjacent lung tissue with wedge resection is used as a palliative replacement surgery for the treatment of lung cancer. At present, with the increase of aging and environmental pollution, the incidence of advanced and non-small cell lung cancer increased, the demand for minimally invasive and retained lung function is increasing, wedge resection gradually become a radical surgery for stage I non-small cell lung cancer [5]. The markers of lung cancer tumor includes Survivin

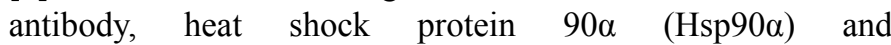
Carcinoembryonic Antigen (CEA), the present study was focused on the application value of the diagnosis of lung cancer and early screening, while the effect of surgery on them is less [6]. In order to study the curative effect of pulmonary wedge resection in the treatment of elderly patients of stage Ia non-small cell lung cancer and the effect on survivin antibodies Hsp90 $\alpha$ and CEA of patients. The patients with stage Ia nonsmall cell lung cancer treated with wedge resection in recent 3 years in our hospital were observed for the effect of treatment 
and detected for the changes of tumor markers in serum. Here the report is as follows.

\section{Materials and Methods}

\section{Clinical data}

32 patients with stage Ia non-small cell lung cancer treated in our department from January 2013 to January 2016 were enrolled, including 20 males and 12 females, aged 70 78 y with an average of $74.8 \pm 3.2,12$ cases of adenocarcinoma, 17 cases of squamous cell carcinoma and 3 cases of squamous cell carcinoma. Pulmonary wedge resection was performed in all the subjects. Inclusion criteria: 1. diagnosis of non-small cell lung cancer based on imaging, histopathology and other data. 2. The TNM stage of lung cancer is stage Ia. 3. The patient signed the informed consent. 4. Age $\geq 70 \mathrm{y}$ old. Exclusion criteria: 1. patients with serious circulatory system and liver and kidney diseases. 2. The staging of lung cancer $\geq$ stage Ib.

\section{Operation method}

The tracheal intubation combined with venous complex general aenesthesia, and also with surgical minimally invasive thoracoscopic resection was employed for wedge section. After fast pathological examination, if diagnosed as non-small cell lung cancer, the lung lobe with the tumor will be resected, and the hilar and mediastinal lymph nodes on the same side will be cleaned systematically. Close the wound and place closed drainage tube after operation.

\section{Observation index}

1. The operation time, blood loss, postoperative infection rate, postoperative 1D drainage and hospitalization time were recorded. 2. The Survivin antibody, Hsp90 $\alpha$ and CEA levels were recorded before and $3 \mathrm{~d}$ after operation. $3 \mathrm{ml}$ peripheral venous blood from patients and healthy controls were taken at the corresponding time points. After coagulation, $2000 \mathrm{r} / \mathrm{min}$ centrifugation for $10 \mathrm{~min}$, serum was separated and stored at $-80^{\circ} \mathrm{C}$. Survivin antibodies and Hsp90 $\alpha$ were detected by Enzyme-Linked Immunosorbent Assay (ELISA) (Bole Life Science Development Co Ltd, Beijing) and double enzyme linked immunosorbent assay (Huyu biological Co., Ltd. Shanghai), the inspection process is carried out according to instructions. The ELISA method was performed using a multishannk 3 automatic enzyme immunoassay instrument. CEA was detected by electrochemiluminescence immunoassay (Huaketai Biotechnology Co. Ltd. Beijing), detection process is followed with the instructions. The radioimmunoassay uses the fully automated chemical immunoassay system for analysis (Abbott Company, USA).

\section{Statistical method}

Observation data were analysed by SPSS18.0, and two groups of measurement data were present as mean \pm standard deviation, and t-test was adopted. $\mathrm{P}<0.05$ means the difference is statistically significant.

\section{Results}

\section{Operation situation}

No death occurred during perioperative period, the average operation time was $38 \sim 98 \mathrm{~min}$, with the average of $71.7 \pm 13.2$ min, the amount of blood loss was $136.2 \pm 32.7 \mathrm{ml}$, and there was no thoracotomy. 2 cases had postoperative pulmonary infection, and were cured after symptomatic treatment. The average flow rate $1 \mathrm{~d}$ after operation was $295.7 \pm 45.4 \mathrm{ml}$, the average postoperative drainage volume was $792.4 \pm 186.2 \mathrm{ml}$, and the average duration of hospitalization was $6.4 \pm 3.1 \mathrm{~d}$.

\section{Comparison of survivin antibody, Hsp90a and CEA levels between the operation group and the healthy control group before surgery}

The levels of serum survivin antibody, Hsp90 $\alpha$ and CEA in the operation group were significantly higher than those in the healthy control group $(\mathrm{P}<0.05)$, as shown in Table 1 .

Table 1. Comparison of survivin antibody, Hsp90a and CEA levels between the operation group and the healthy control group before surgery $(\bar{x} \pm s)$.

\begin{tabular}{|c|c|c|c|c|c|}
\hline Groups & $\mathbf{n}$ & $\begin{array}{l}\text { Survivin } \\
\text { (pg/ml) }\end{array}$ & antibody & Hsp90a ( $\mu \mathrm{g} / \mathrm{L})$ & CEA $(\mu \mathrm{g} / \mathrm{L})$ \\
\hline $\begin{array}{l}\text { Operation } \\
\text { group }\end{array}$ & 32 & $52.1 \pm 28.7$ & & $250.2 \pm 120.7$ & $11.2 \pm 4.1$ \\
\hline Control group & 32 & $9.5 \pm 3.2$ & & $41.5 \pm 7.4$ & $2.3 \pm 1.1$ \\
\hline $\mathrm{t}$ & l & 8.345 & & 9.763 & 11.860 \\
\hline$P$ & l & $<0.001$ & & $<0.001$ & $<0.001$ \\
\hline
\end{tabular}

\section{Comparison of survivin antibody, Hsp90a and CEA levels before and after operation}

The levels of serum survivin antibody, Hsp90 $\alpha$ and CEA in patients after operation were significantly lower than those before operation $(\mathrm{P}<0.05)$ (Table 2$)$.

Table 2. Comparison of survivin antibody, Hsp90a and CEA levels before and after operation $(\bar{x} \pm s)$.

\begin{tabular}{|c|c|c|c|c|c|}
\hline Time & $\mathbf{n}$ & $\begin{array}{l}\text { Survivin } \\
\text { (pg/ml) }\end{array}$ & antibody & Hsp90a ( $\mu \mathrm{g} / \mathrm{L})$ & CEA $(\mu \mathrm{g} / \mathrm{L})$ \\
\hline $\begin{array}{l}\text { Before } \\
\text { surgery }\end{array}$ & 32 & $52.1 \pm 28.7$ & & $250.2 \pm 120.7$ & $11.2 \pm 4.1$ \\
\hline After surgery & 32 & $20.5 \pm 13.2$ & & $122.4 \pm 47.3$ & $6.3 \pm 2.1$ \\
\hline $\mathrm{t}$ & 1 & 5.659 & & 5.577 & 6.017 \\
\hline$P$ & I & $<0.001$ & & $<0.001$ & $<0.001$ \\
\hline
\end{tabular}

\section{Comparison of recurrence and the levels of survivin antibody, Hsp90o and CEA in the patients after surgery}

As shown in Table 3, the patients were followed up for 14 50 months, and 5 cases of recurrence and 3 cases of metastasis. 
The levels of Survivin antibody, Hsp90 $\alpha$ and CEA in patients with recurrence and metastasis were significantly higher than those without recurrence or metastasis.

Table 3. Comparison of the levels of survivin antibody, Hsp90a and CEA between the patients with recurrence and metastasis and the patients without recurrence or metastasis $(\bar{x} \pm s)$.

\begin{tabular}{|c|c|c|c|c|c|}
\hline Time & $\mathbf{n}$ & $\begin{array}{l}\text { Survivin } \\
\text { (pg/ml) }\end{array}$ & antibody & Hsp90a $(\mu \mathrm{g} / \mathrm{L})$ & CEA $(\mu \mathrm{g} / \mathrm{L})$ \\
\hline $\begin{array}{l}\text { Recurrence } \\
\text { group }\end{array}$ & 8 & $29.1 \pm 18.4$ & & $161.3 \pm 79.5$ & $8.3 \pm 3.2$ \\
\hline $\begin{array}{l}\text { Non-recurrence } \\
\text { group }\end{array}$ & 24 & $17.5 \pm 7.8$ & & $105.4 \pm 34.3$ & $5.7 \pm 1.9$ \\
\hline $\mathrm{t}$ & I & 5.659 & & 5.577 & 6.017 \\
\hline$P$ & l & $<0.001$ & & $<0.001$ & $<0.001$ \\
\hline
\end{tabular}

\section{Discussion}

Lung cancer is one of malignant tumors with the highest incidence of mortality in clinical in the world, the number of deaths caused by lung cancer was the most in all the cancers. In our country, deaths caused by lung cancer accounted for $22.7 \%$ of all cancer patients [7]. In recent years, with the process of industrialization and urbanization, China's aging trend has become increasing, and smoking rates remain high, the incidence of lung cancer among elderly people is also increasing, leading to an annual growth of $27 \%$ [8]. Nearly $70 \%$ of lung cancer is Non-Small Cell Lung Cancer (NSCLC), characterized by a low degree of deterioration and a slow progression in the course of the disease. It is easy to develop micrometastasis at the time of advanced detection. Therefore, the early detection and early treatment of non-small cell lung cancer is the key to the success treatment and to prevent the progression of the disease. For the early diagnosis of cancer, tissue biopsy is an invasive examination, and restricted by many factors, while imaging is more expensive, and the small lesions is difficult to be found, so the serum tumor markers become a convenient, cheap and reproducible means of screening for early lung cancer. For early NSCLC, surgery is still the preferred mean [9]. Surgical procedures must be accompanied by trauma and impairment of lung function. With the increase of aging, the incidence of non-small cell lung cancer in elderly patients is increased, who cannot tolerate surgery loss and the impairment of lung function, it is necessary to find a more suitable operation to improve the quality of life of patients after surgery. Wedge resection is used to resect only the tumor and adjacent lung tissue, and has minimal impact on lung function. It is now being used more and more in the surgical treatment of elderly patients with early NSCLC. Lung cancer tumor markers includes Survivin antibody, Hsp90 $\alpha$ and CEA, the present study was focused on the application value of the diagnosis of lung cancer and early screening, while the effect of surgery on them is less.

In this study, no death occurred during perioperative period, the average operation time was 40 97 min, with the average of $71.7 \pm 13.2 \mathrm{~min}$, the amount of blood loss was $136.2 \pm 32.7 \mathrm{ml}$, and there was no thoracotomy. 2 cases had postoperative pulmonary infection, and were cured after symptomatic treatment, indicating pulmonary wedge resection has the advantages of shorter operation time, less damage and less postoperative lung infection. The patients were followed up for 14 50 months, and 5 cases of recurrence and 3 cases of metastasis. Although some studies have pointed out that the lung resection range of wedge resection is small, which cannot completely resect surgical margin and residual micrometastasis of lymph node and increased risk of recurrence, but for the elderly patients with lung cancer, too much emphasis on radical surgery will increase the loss of lung function and surgical trauma, may reduce the quality of life and shorten the survival time. The advantage of pulmonary wedge resection is that it can preserve healthy lung tissue in a large extent, reduce operative complications and operative mortality, and improve the recovery and quality of life in patients $[10,11]$. The levels of serum survivin antibody, Hsp90 $\alpha$ and CEA in patients before surgery were significantly higher than those in healthy controls, suggesting the three are effective tumor markers and can be used in the early screening of NSCLC. The serum survivin antibody, Hsp90 $\alpha$ and CEA levels were significantly lower in patients after operation than those before surgery, but still higher than those in the healthy controls. The sruvivin gene is not expressed in adult healthy tissues, but expressed in malignant tumors $[12,13]$. After the wedge resection, the level of serum survivin antibodies produced by the immune system is reduced due to the removal of primary lesions. Hsp90 $\alpha$ is an active molecular chaperone in the tumor, is a recently discovered biomarker of lung cancer, which is not only in tumor tissues, and secreted into the extracellular, involved in tumor invasion and metastasis [14,15]. After tumor resection, the serum levels of Hsp90 $\alpha$ also decreased; CEA as a sugar protein expressed in tumors, is a broad-spectrum tumor marker $[16,17]$, resection of lesions could reduce the serum level of CEA. At the same time, recurrence and metastasis in patients with postoperative Survivin antibody, Hsp90 $\alpha$ and CEA were significantly higher than that of non-recurrence and metastasis in patients, indicating that the three can be used as good indexes for monitoring and prognosis.

Therefore, in clinical practice, pulmonary wedge resection for the treatment of elderly patients with early non-small cell lung cancer is suitable for the patients who are not tolerable to the loss of lung tissue, and there is no significant difference of disease-free survival and overall survival compared with the lobectomy patients $[18,19]$. The comparison of serum survivin antibody, Hsp90 $\alpha$ and CEA levels before and after surgery demonstrated that the three levels were significantly higher than those in the healthy population before surgery; and pulmonary wedge resection can reduce levels of the three tumor markers; the three levels in patients with recurrence and metastasis were higher than those of non-recurrence patients. All these indicate that serum survivin antibody, Hsp90 $\alpha$ and CEA can be used as good indicators of non-small cell lung cancer screening, and may also become important prognostic indicators after surgery. Since the sample size is small, more 
accurate conclusions need to be confirmed by multicenter studies with large sample size.

\section{References}

1. Dong L, Li JH. Progress in the maintenance therapy of advanced non-small cell lung cancer. Chinese N Drug Clin J 2015; 1: 5-11.

2. Zhao ZZ, Wang ZM, Mao AW. The interventional treatment of non-small cell lung cancer. J Interv Radiol 2014; 23: 272-276.

3. Zhang H, Shen-Tu Y. Clinical advance of sublobectomy for early stage non-small cell lung cancer. Zhongguo Fei Ai Za Zhi 2015; 18: 565-570.

4. Taioli E, Lee DS, Lesser M. Long-term survival in videoassisted thoracoscopic lobectomy vs open lobectomy in lung-cancer patients: a meta-analysis. Off J Eur Assoc Cardio Thorac Surg 2013; 44: 591-597.

5. Liu Q. Comparison of clinical outcomes after thoracoscopic sublobectomy versus lobectomy for Stage I nonsmall cell lung cancer: a meta-analysis. J Can Res Ther 2016; 12: 926.

6. Song S, He X. Expression of MMP-9 and TIMP-1 in NSCLC and adjacent tissues and its clinical significance. J Mod Oncol 2013; 15: 6446-6455.

7. $\mathrm{Fu} \mathrm{ZQ}$, Zhou Q. Comparative analysis of clinical data of elderly lung cancer patients with lung cancer. China Oncol 2015; 25: 624-628.

8. Lung cancer group of Chinese medical association, China lung cancer control association. Early diagnosis of primary bronchogenic carcinoma of China (draft). Chin J Tuberc Respir Dis 2014; 37: 172-176.

9. Tarasevych S, Lauwers P, Vandaele F, van Meerbeeck JP. Novel treatment options in stage I non-small-cell lung cancer. Expert Rev Anticancer Ther 2014; 14: 1007-1020.

10. Nomori H, Cong Y, Sugimura H. Limited thoracotomy for segmentectomy: a comparison of postoperative pain with thoracoscopic lobectomy. Surg Today 2016; 46: 1243-1248.

11. Liu C. Long term outcomes of patients with stage I lung cancer treated by single-direction video-assisted thoracoscopic surgery lobectomy or segmentectomy.
Zhonghua Wai Ke Za Zhi Chinese J Surg 2015; 53: 742-746.

12. Vischioni B, Oudejans JJ, Kruyt FA, Giaccone G, Rodriguez JA. Immunohistochemical detection of nuclear survivin in NSCLC: a comparison of commercial antibodies. Histopathology 2007; 50: 671-675.

13. Wang J, Liu C, Zhong D, Xu D, Ning C, Ma Q. Immunohistochemical detections of EGFR status in NSCLC. Zhongguo Fei Ai Za Zhi 2015; 18: 212-218.

14. Seo YH. Discovery of 2, 4-dimethoxychalcone as a Hsp90 inhibitor and its effect on iressa-resistant non-small cell lung cancer (NSCLC). Arch Pharm Res 2015; 38: 1783-1788.

15. Tung CL, Jian YJ, Syu JJ. Down-regulation of ERK1/2 and AKT-mediated X-ray repair cross-complement group 1 protein (XRCC1) expression by Hsp90 inhibition enhances the gefitinib-induced cytotoxicity in Human lung Cancer cells. Exp Cell Res 2015; 334: 126-135.

16. Facchinetti F, Aldigeri R, Aloe R. CEA serum level as early predictive marker of outcome during EGFR-TKI therapy in advanced NSCLC patients. Tumor Biol 2015; 36: 5943.

17. Zhang Y, Han B, Jin B. 121P serum carcinoembryonic antigen levels predicts the efficacy of EGFR-TKI in nonsmall cell lung cancer harboring EGFR mutations. J Cancer Res Ther 2016; 26: 254-258.

18. Zhang XQ, Yue DS, Wang CL. Two kinds of surgical treatment of elderly? prognostic analysis of non-small cell lung cancer. Chinese J Clin Oncol 2015; 42: 386-391.

19. Wang K. The analysis of the efficacy of laparoscopic pulmonary wedge resection and lobectomy for early lung cancer. J Clin Surg 2016; 24: 228-230.

\section{*Correspondence to}

Chun-xi Zheng

Qingdao Commercial Worker's Hospital Qingdao

Shangdong

PR China 